\title{
Experimental analysis of the effect of magnesium saltwater influx on the behaviour of drilling fluids
}

\author{
Olufemi A. Adekomaya
}

Received: 19 August 2011/Accepted: 2 December 2012/Published online: 18 December 2012

(C) The Author(s) 2012. This article is published with open access at Springerlink.com

\begin{abstract}
This paper presents an experimental analysis of drilling fluid at elevated temperatures with and without magnesium saltwater influx in order to determine how these fluids behave when encountering the influx of salinity formation water. Salt contamination can come from drilling salt beds, or from a formation water influx. Salt water which contains magnesium chloride was added systematically to the formulated mud systems in order to evaluate its effects on the drilling fluid at elevated temperature conditions. It was observed that rheological changes in drilling fluids due to influx of magnesium salts have many effects on the degree of efficiency at which the drilling fluid performs its primary functions. From the analysis, it was observed that small quantities of magnesium saltwater can be removed with caustic soda but the large quantities are detrimental to rheological properties of drilling muds used in Niger formation.
\end{abstract}

Keywords Drilling fluid - Saltwater - Weighting agent · Temperature

$\begin{array}{ll}\text { Abbreviations } \\ \text { OBM } & \text { Oil-based mud } \\ \text { HT-HP } & \text { High temperature high pressure } \\ \text { ES } & \text { Electrical stability (volts) } \\ \text { YP } & \text { Yield point (lb/100 sq. ft) } \\ \text { WBM } & \text { Water-based mud }\end{array}$

O. A. Adekomaya ( $\square)$

Department of Petroleum and Gas Engineering,

University of Lagos, Lagos, Nigeria

e-mail: oadekomaya@unilag.edu.ng

\section{Introduction}

Drilling fluids are either water based or oil based. These fluids are made up of a base fluid, water or diesel (hydrocarbon), weighting agents and other additives that aid in removing the cuttings from the wells and keep the mud in a fluid state (Alotaibi et al. 2010). The behaviour of the drilling fluids under high temperature and high pressure is extremely important for drilling deep wells. At temperatures higher than $200{ }^{\circ} \mathrm{F}\left(94{ }^{\circ} \mathrm{C}\right)$, the hydroxyl-ion/clay interaction occurs at rates sufficient to change the rheological behaviour of the fluid (Darley and Generes 1956; Sydansk 1983). During the circulation downhole and back to the surface, the mud picks up contaminants (extraneous materials not present when the fluid was originally formulated). Drill solids, cement, and salts are common contaminants. At low temperatures, the mud may be able to tolerate the contaminants, but at elevated temperatures, remedial measures are often necessary. The savings in time, money and manpower are obvious to engineers, drilling managers, and laboratory personnel accustomed to waiting out the tedious weeks required for conventional bomb methods. Moreover, comparisons with conventional methods indicate two further superior features of this new circulation system: mud and mud components stabilize more completely; and laboratory muds thus produced more accurately represent good field muds produced after extended high temperature drilling (Reece 1975). Problems associated with drilling fluids normally occur downhole, so it is reasonable to be interested in the properties of drilling fluids at the conditions which exist downhole. While the general practice is to measure drilling fluid density and rheological parameters at the surface, and use these parameters to estimate pressures in the wellbore, several authors have studied the effects of pressure and temperature 
on the rheological and density of drilling fluids. This is because many studies have shown that estimated pressure losses using surface properties do not match the actual pressure losses measured in the fluid (Zamora 1996; White et al. 1996; Davison et al. 1999). McLean et al. (1967) showed that the rheological properties of a mud under downhole conditions are very important to cementing operations. Burkhardt (1961) showed that a knowledge of rheological properties of muds under downhole conditions is necessary to predict pressure surges. De Wolf et al. (1983) reported a close correlation of the results from their study of less toxic oils to the Herschel-Bulkley model. It was also observed that the magnitude of viscosity difference between oils tends to decrease with temperature in spite of pressure indicating that temperature was the more dominant factor. Hiller (1963) and Annis (1967) studied the effects of high temperatures (up to $150{ }^{\circ} \mathrm{C}$ ) and pressures (up to 500 bar) on the rheology of water-base mud, and concluded that high temperature caused flocculation of the bentonite mud. Rommetveit and Bjørkevoll (1997)conducted laboratory measurements and concluded that rheology is pressure and temperature dependent. Sinha (1970) investigated water-based clay suspensions as well as oil-base muds using a falling bob consistometer concluding that the equivalent viscosity of WBM is not affected to the same extent by the variations of temperature and pressure. $\mathrm{He}$ also concluded that the temperature is the dominating variable in the case of WBM. Much has been written on how various electrolytes affect rheological proper ties at room temperature (Hauser and Reed 1937; Street 1958; Garrison and Tep Brink 1939; Browning and Perricone 1963). The solid fraction of a mud usually causes the most significant, and certainly the most unpredictable, changes in mud properties at elevated temperature. Different types of solids have different shapes, sizes and surface charges; hence, they behave differently when suspended in a liquid and subjected to elevated temperatures (Annis 1967). Improperly formulated and maintained drilling fluid systems can cause significant near-wellbore formation damage and create potential for the plugging of screens and slotted liners (Pitoni et al. 1999). Rheological changes in drilling fluids have many effects on the degree of efficiency with which a fluid performs its primary functions. Many researchers have worked on the effects of temperature and pressure on the drilling fluid but none of them has ever researched on the effect of magnesium saltwater on the drilling fluid performance. However, the major effect of magnesium is to react with hydroxyls in the mud system, thus depleting mud alkalinity and $\mathrm{pH}$. This can in turn allow the undesirable carbonate and bicarbonate components of alkalinity to become dominant. Small quantities of magnesium such as those present in saltwater can be readily removed with additions of caustic soda. When large quantities of magnesium are encountered (magnesium shale, evaporates or brine flow), it is not practical to treat out the contaminant. The paper focuses on the effect of magnesium saltwater influx on the performance of drilling fluid at elevated temperature in order to know how the fluid reacts in a downhole conditions.

\section{Laboratory mud formulation}

The main objective in testing the laboratory-formulated drilling fluids was to compare oil mixed with water, emulsifier, viscosifiers and other additives with different weighting agents, barite (Barium Sulphate) which has density of 4.5 and SG of $35 \mathrm{ppg}$, and hematite (Iron Oxide) which has density of 5.3 and SG of 44.15 ppg and ferrobar (combination of barite and hematite) in order to evaluate their performance in a downhole condition. The formulated muds in this study consist of diesel oil and water at a ratio of 75/25. OBM are composed of brine droplet in an organic phase (base oil). The continuous phase and suspending medium for solids (or liquid) is a water immiscible fluid that is oil-based. The presence of emulsifier and co-emulsifier such as VERSAMUL and VERSACOAT is necessary to ensure a good stability of the emulsion, HPHT filtration control and also to reduce the effects of water contamination. Depending on the formulation, different additives that may be present among them are viscosifying agents such as VERSAGEL HT (amine-treated, pure hectorite clay used as the primary viscosifier in invert emulsion drilling fluid systems), lime in order to control mud alkalinity, filtrate reducers, wetting agent to ensure mud homogeneity. Rheological properties of the base oil were measured and correlated with the mud properties. This was used to determine the influence of the nature of the based oil and of the type of additives present in the formulation. Three samples of formulated mud were used as Sample A containing all the above-listed composition with ferrobar as weighting agent, Sample B containing barite and Sample C containing hematite to regulate mud density. Mud mixer was used to mix the three portions of mud samples to ensure homogeneous mixture. For the purpose of the following tests, a high-temperature/high-pressure rotational viscometer was used. This viscometer was capable of measuring drilling fluids properties from ambient to $500{ }^{\circ} \mathrm{F}$ at gauge pressures from 0 to 12,000 psi. The mud properties were measured before aging at $120^{\circ} \mathrm{F}$ at a pressure of $500 \mathrm{psi}$ and aged at 400 and $500{ }^{\circ} \mathrm{F}$ at 10,000 and $12,000 \mathrm{psi}$ for $16 \mathrm{~h}$ at dynamic condition and the rheological properties were taken at $120^{\circ} \mathrm{F}$ after aging. The filtrates were run for 30 min upon which the volume of filtrate was recorded and the filter cake thickness was measured. These viscometers have rotation speeds 
$(600,300,200,100,60,30$ and $3 \mathrm{rpm})$ as recommended by API to measure the rheological properties of drilling mud samples. The laboratory experiment was carried out in phases with the mud volume of $350 \mathrm{~cm}^{3}$. In the first phase of testing, no salt water was introduced and temperature was taken at $120^{\circ} \mathrm{F}$ and aged at 400 and $500{ }^{\circ} \mathrm{F}$ and the rheological properties of these fluids were determined at $120^{\circ} \mathrm{F}$ for the three different mud formulations. The second phase was carried out in similar manner but with the addition of $30 \mathrm{ml}$ of salt water (which contains magnesium salt water, $\mathrm{MgCl}_{2}$ ) to the same volume specified above to evaluate its effects on the rheological properties of these fluids.

\section{Objectives}

1. To study which of the drilling fluids will perform best when there is magnesium saltwater influx.

2. To study drilling fluid flow behaviour at low and high temperatures.

3. To study the effect of magnesium saltwater influx on commonly used drilling fluid at elevated temperatures.

4. To determine effectiveness, temperature stability and overall characteristics of mud components to mimic downhole conditions.

\section{Analysis of results}

\section{Effect of temperature on the drilling mud}

As shown in Figs. 1 and 2, yield point and gel strength decrease gradually with increase in temperature. These changes in rheological properties can be explained according to the investigation done by Al-Marhoun and Rahman (1988). According to them, these changes in rheological properties are due to the effect of lime added to the mud system. With the application of heat and lime release a large amount of calcium ions in aqueous solution. Calcium ions replace sodium ions from the crystal lattice of the clay platelets, thus resulting in calcium-base clay. Due to the interparticle forces of calcium-base clay, the platelet aggregates. As the ion exchange continues, the platelets collapse upon each other and lead to a state of aggregation. As a result of continuous flocculation and the aggregation of platelets, there is an overall reduction in solid volume, thus enabling the clay aggregates to move freely through the aqueous phase with the consequent lowering of the internal friction. From Fig. 1, it can be deduced that at $120^{\circ} \mathrm{F}$, the mud particles are charged so that they attracted each other. Exposure to high temperature for a long period of time caused degradation in the mud system thereby leading to particles repulsion towards one another. The

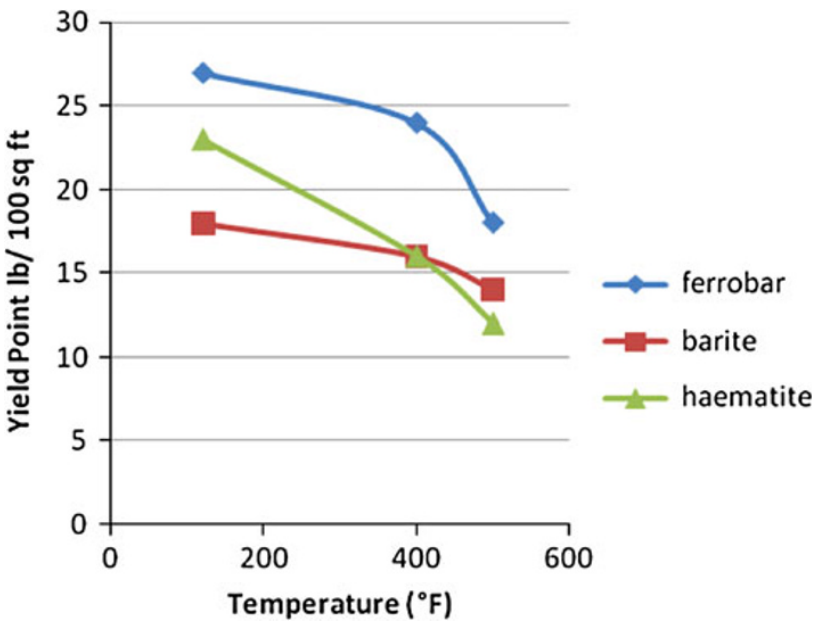

Fig. 1 Plot of yield point against temperatures on three different mud samples before salt contamination

three muds experienced particles dispersion at the same temperature with different yield points. Due to the high yield point of ferrobar, we can conclude that it increases the carrying capacity of the mud which aids hole clearing although it may not be necessary in high weight muds to insure good cutting carrying capacity. Figure 2 shows that the three muds experienced mud sagging, failure to tolerate higher density and degradation in the form of gelation at the bottom hole temperature of $400{ }^{\circ} \mathrm{F}$. The temperature at which a very rapid decrease in gel strength occurs indicates the onset of deflocculating. From the state of gel, mud fluidification was observed at temperature above $400{ }^{\circ} \mathrm{F}$. During a circulation stop, the drilling mud cools down to a very low temperature and gives rise to a gel. Recirculation after such a rest period demands a pressure surge to break the gel. Figure 3 shows that as temperature increases, there is progressive fluid loss into the formation. Barite mud which is generally used for drilling operation experienced

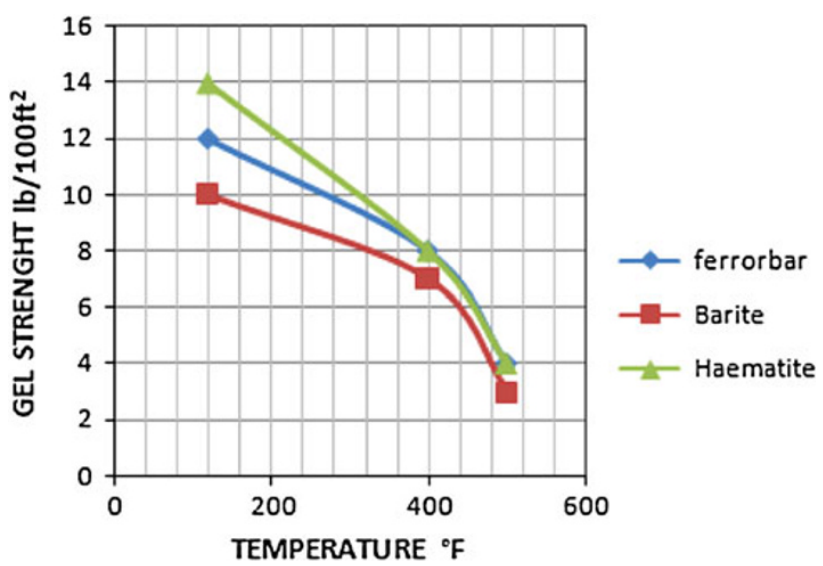

Fig. 2 Plot of gel strength against temperatures on three different mud samples 


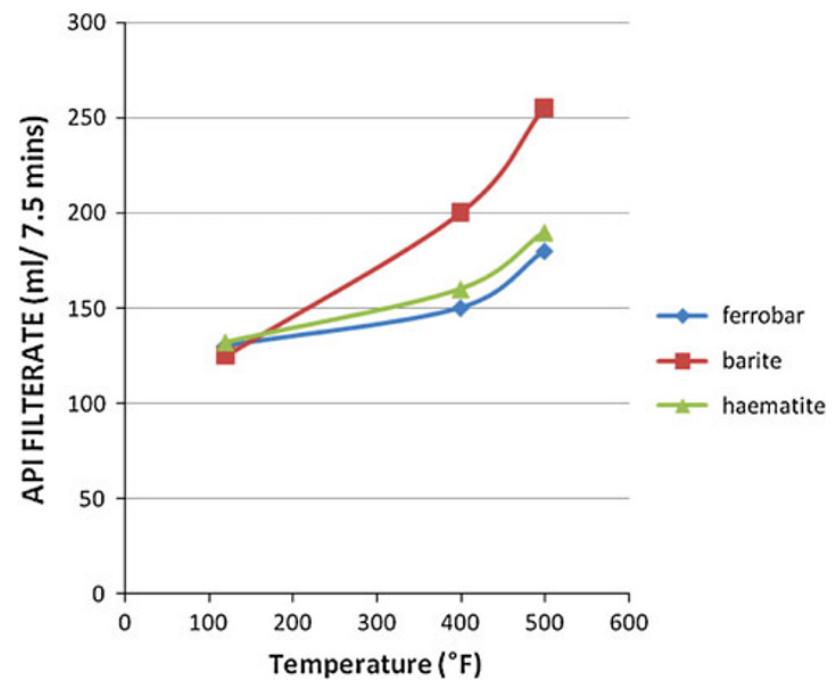

Fig. 3 Plot of fluid loss against temperatures on three different mud samples

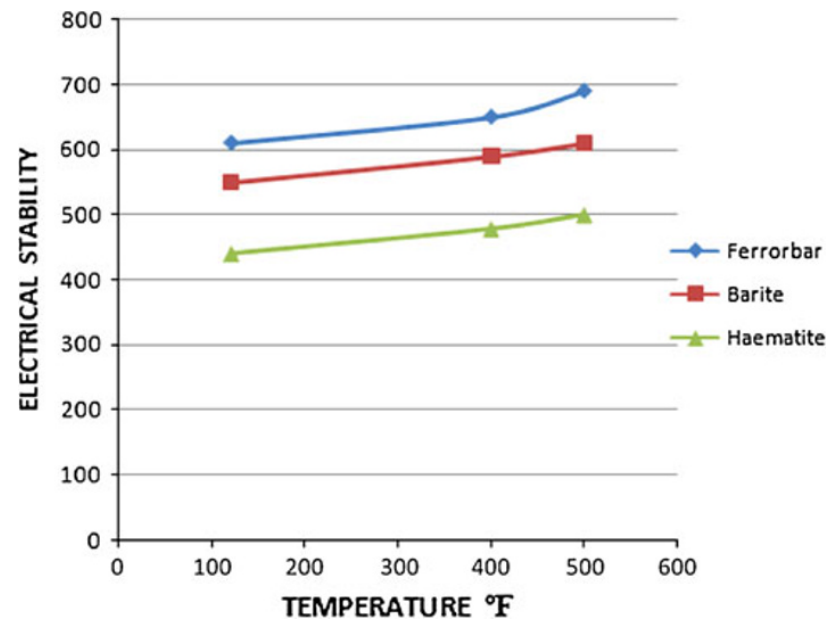

Fig. 4 Plot of electrical stability against temperatures on three different mud samples

higher fluid loss into the formation at high temperature than other muds which indicates that barite mud has the tendency to experience differential sticking as the temperature increases before other two muds, while ferrobar mud provides satisfactory rheological properties required for optimum performance in oil well drilling at elevated temperatures. From Fig. 4, it shows that ferrobar mud has the highest ES than barite and haematite muds which indicate that ferrobar has the tendency to maintain a strong emulsifying strength as the reservoir temperature increases. Figure 5 shows the plastic viscosity against temperature. The first noticeable effect is the rise in viscosity of ferrobar which occurs when observed under the temperature of $400{ }^{\circ} \mathrm{F}$ with increasing pressure (Fig. 5). The barite and

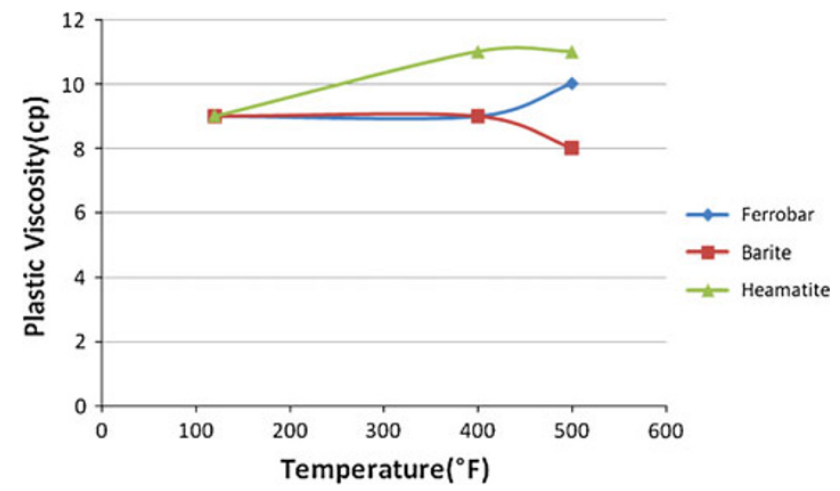

Fig. 5 Plot of plastic viscosity against temperatures on three different mud samples

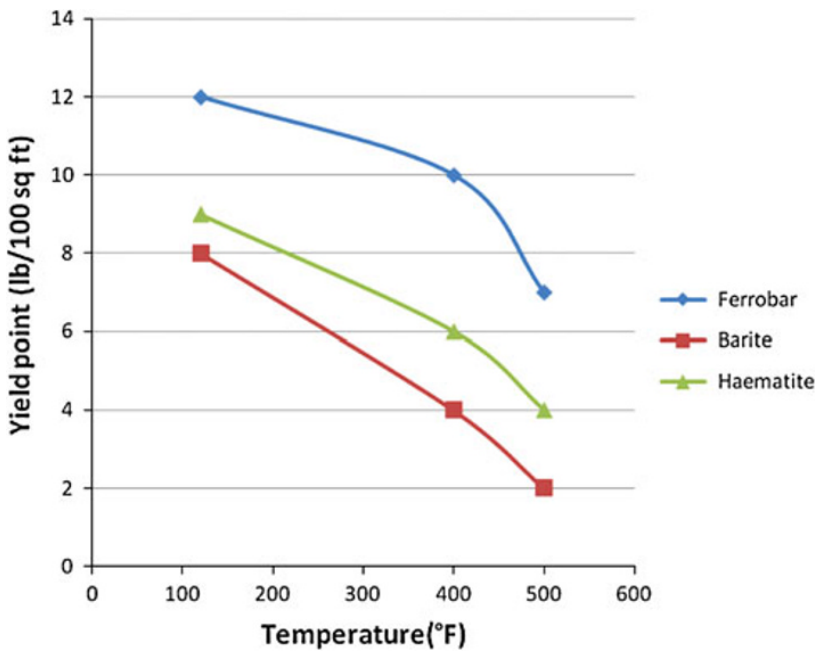

Fig. 6 Effects of magnesium saltwater on the yield points of mud samples

hematite tend to decline at $400^{\circ} \mathrm{F}$. The decline in plastic viscosity shows that at temperature above $400{ }^{\circ} \mathrm{F}$, barite and hematite lose their resistance to flow.

\section{Effect of salt on drilling mud}

Figure 6 above shows that with the magnesium saltwater influx, there is progressive decline in the performance of barite and hematite muds which indicates that saltwater affects the hydration, dispersion and flocculation behavior of the viscosifier and weighting agent causing particles dispersion and increasing the number of individual platelets in suspension which renders it ineffective for cutting lifting while ferrobar mud shows that cutting suspensions are maintained with the influx of magnesium saltwater at elevated temperature. From Fig. 7, it shows that when a barite mud is quiescent, the gelation process depends on both time and temperature as barite maintains a progressive 


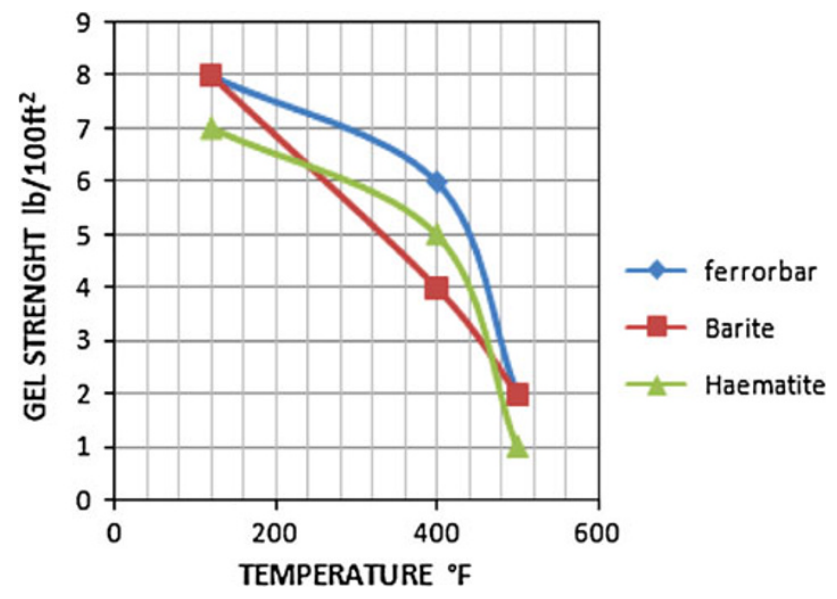

Fig. 7 Effects of magnesium saltwater on the gel strength of mud samples

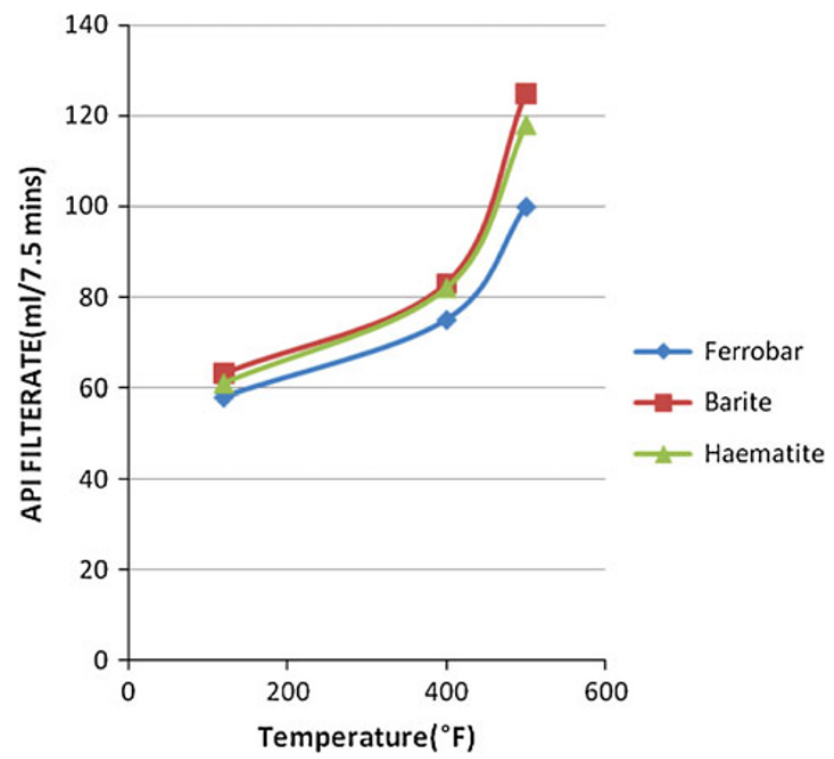

Fig. 8 Effects of magnesium saltwater on fluid loss in the mud samples

decline in gel strength at high temperature making recirculation difficult. However, ferrobar and hematite experienced thermal degradation as temperature increases. This indicates that the muds are not likely to be good weighting and cutting suspender with saltwater influx. From Fig. 8, we can conclude that as the hydrostatic head of the drilling fluid is higher than the pore pressure in the formation, liquid from barite and hematite muds will be forced into the formation which thereby causes productivity loss, while

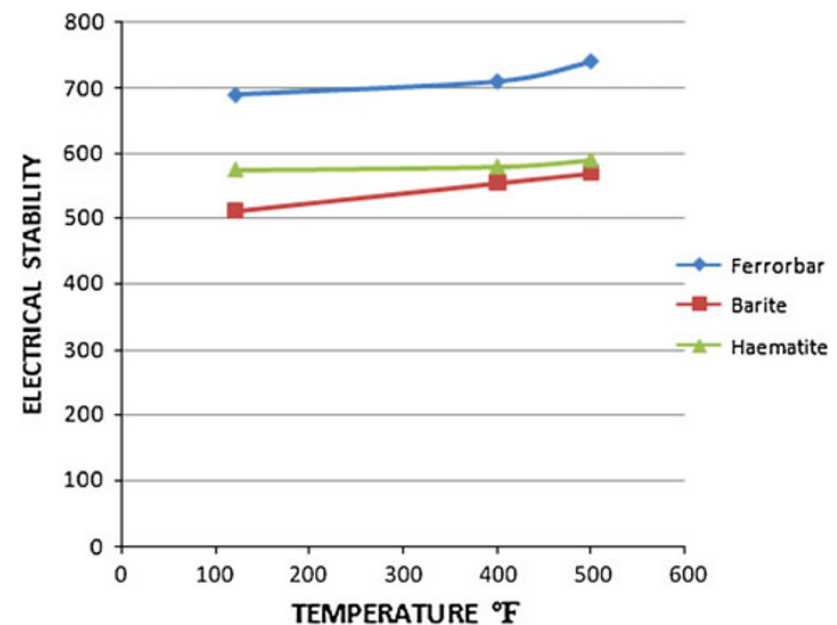

Fig. 9 Effects of magnesium saltwater on the electrical stability in the mud samples

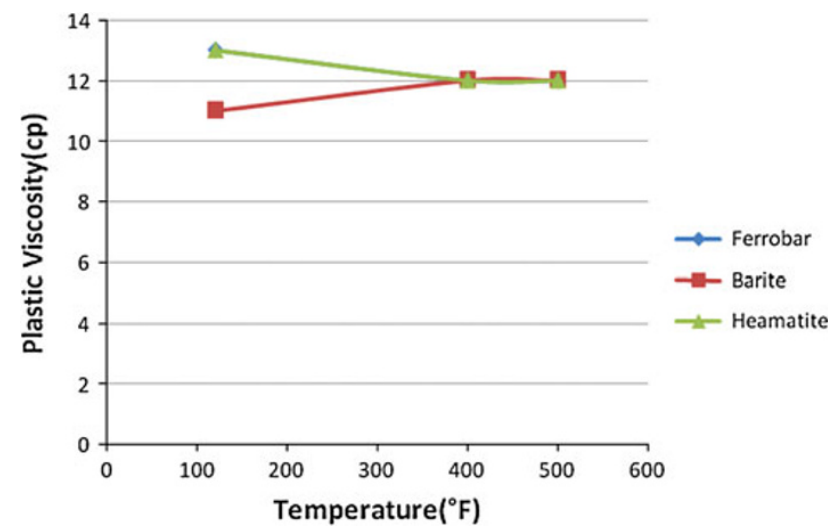

Fig. 10 Effects of magnesium saltwater on the plastic viscosity in the mud samples

ferrobar mud maintains minimal fluid loss into the formation matrix among the three muds in a saline environment. Figure 9 shows the effects of magnesium saltwater influx on the ES in the mud samples. From the plot, it is discovered that an increase in temperature augments the ionic activity of any electrolyte and the solubility of any partially soluble salt that may be present in the muds. This alters the balance between the interparticle attractive and repulsive forces and the degree of dispersion and flocculation of the mud systems which deeply affect the emulsion stability of oil base muds. Figure 10 shows effect of plastic viscosity against temperature. From the figure, the plastic viscosity of barite was higher at temperature above $380^{\circ} \mathrm{F}$ until a temperature of $400{ }^{\circ} \mathrm{F}$ after which the viscosity of the three mud samples was approximately similar. 


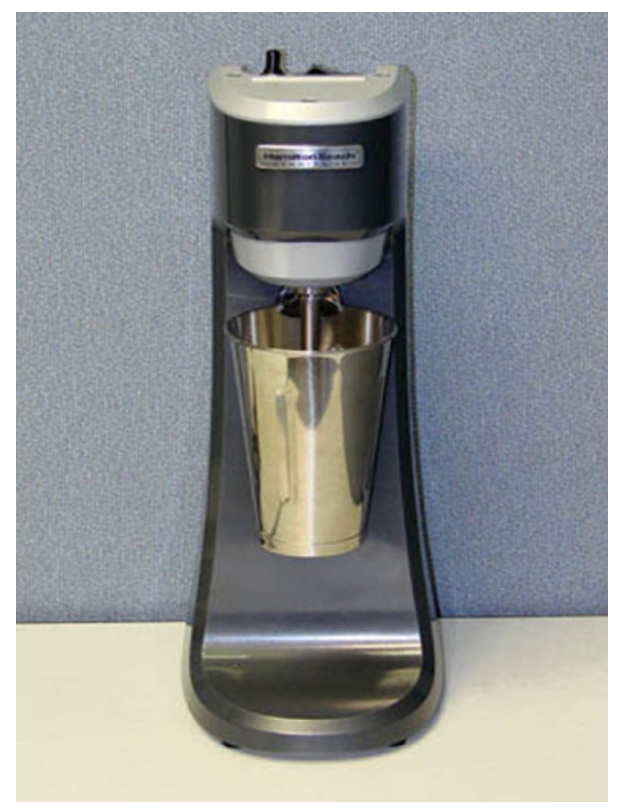

Fig. 11 Mud mixer

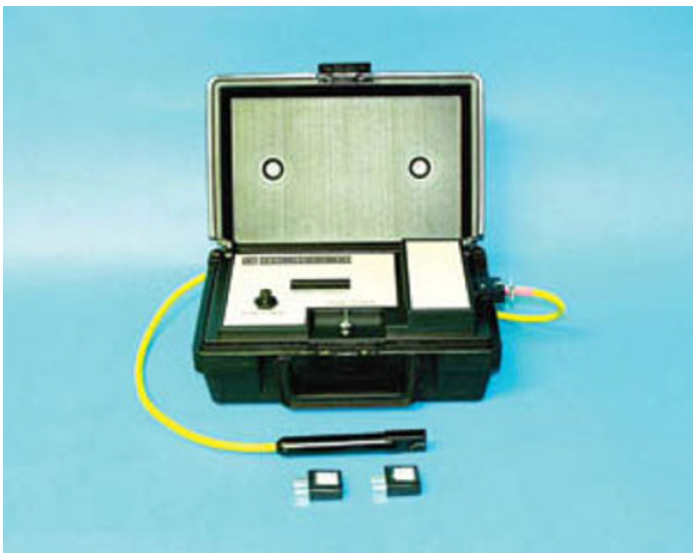

Fig. 12 Electrical stability meter

\section{Conclusions}

1 It is very important to know precisely the temperature evolution of the drilling mud during the different drilling and circulation stop.

2 From the research carried out, it was observed that increase in temperature reduces the stability and viability of drilling fluid.

3 It is revealed that at temperature above $400{ }^{\circ} \mathrm{F}$, ferrobar, barite and hematite fluids lack important rheological properties.

4 Considering the thermal degradation effect on the three muds, we can conclude that ferrobar maintains its effectiveness to flow at temperature above $500{ }^{\circ} \mathrm{F}$.

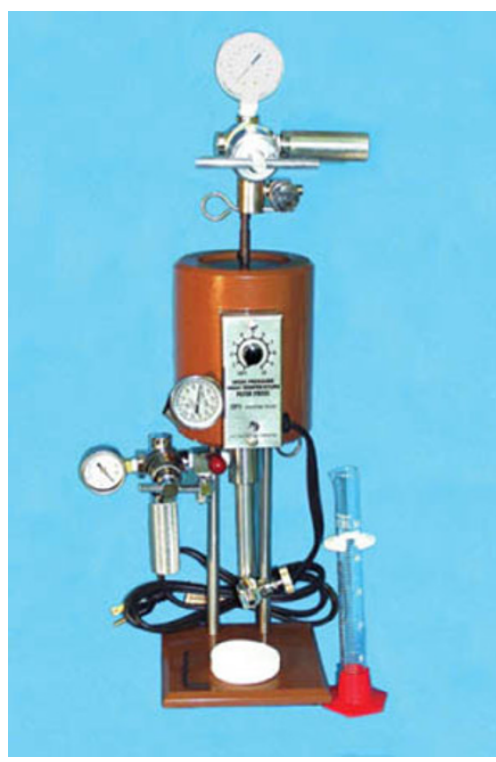

Fig. 13 HTHP filter press

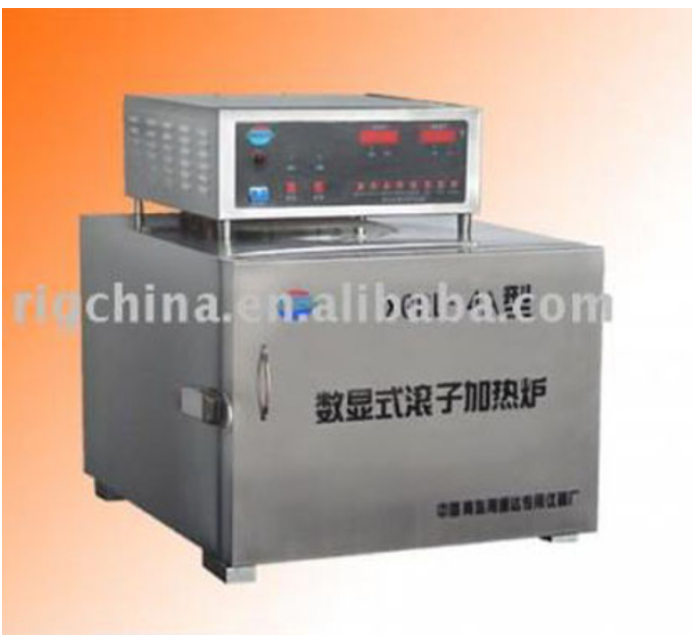

Fig. 14 Roller oven

Acknowledgments The authors would like to thank all the staff of MiSWACO, Port Harcourt Nigeria for their technical support and the resources made available during the experimental work of this research.

Open Access This article is distributed under the terms of the Creative Commons Attribution License which permits any use, distribution, and reproduction in any medium, provided the original author(s) and the source are credited.

\section{Appendix: Description of equipment used}

Mud mixer

This is an apparatus use in the mud laboratory to mix mud at high rotor speed. It consist of a stand in which an 
elongated thin rod is attached; at the end of the rod is rough edged fan blade which act as the rotor and at different speed ensures a homogenous mixture (Fig. 11).

\section{Electrical stability meter}

The OFITE electrical stability meter (ES) is a sine wave instrument manufactured in accordance with the American Petroleum Institute (API) "Recommended Practice Standard Procedure for Field Testing Oil-Based Drilling Fluids". It is accurate, compact and portable and is intended for routine field and laboratory use to measure the relative electrical strength of drilling fluids having a continuous oil phase (Fig. 12).

\section{A HTHP filter press}

This apparatus is used to heat the fluid in a controlled environment to a temperature that is expected in the well (Fig. 13).

\section{Roller oven}

This is an enclosed compartment for heating. This particular involves flat steel inserted from end to end are in constant rolling, the cells containing the mud are in placed on it for dynamic aging (Fig. 14).

\section{References}

Al-Marhoun MA, Rahman SS (1988) Optimizing the properties of water-based polymer drilling fluids for penetrating formations with electrolyte influx, Erdol Erdgas, pp 318-323
Alotaibi MB, Nasr-El-Din HA, Hill AD, Moajil AM (2010) An optimized method to remove filter cake formed by formate-based drill-in fluid in extended reach wells, SPE 109754

Annis MR (1967) High temperature flow properties of water-base drilling fluids. J Petrol Technol 19:1074-1080

Browning WC, Perricone AC (1963) Clay chemistry and drilling fluids, SPE 540

Burkhardt JA (1961) Wellbore pressure surge produced by pipe movement. J Petrol Technol 13:595-605

Darley HCN, Generes RA (1956) The use of barium hydroxide in drilling muds. Trans AIME 207:252-255

Davison JM, Clary S, Saasen A, Allouche M, Bodin D, Nguyen VA (1999) Rheology of various drilling fluid systems under deepwater drilling conditions and the importance of accurate predictions of down hole fluid hydraulic, SPE 56632

De Wolf RC, Coffin GB, Byrd RV (1983) Effects of temperature and pressure on rheology of less toxic oil mud, SPE 11892

Garrison AD, Tep Brink KC (1939) A study of some phases of chemical control in clay suspension. Transaction AIME

Hauser EA, Reed CE (1937) The thixotropic behaviour and structure of bentonite. J Phys Chem 41:910-934

McLean RH, Mary CW, Whitaker WW (1967) Displacement mechanics in primary cementing. J Petrol Technol 19:251-260

Pitoni E, Ballard DA, Kelly RM (1999) Changes in solids composition of reservoir drill in fluids during drilling and the impact on filter cake properties, SPE 54753

Reece W, Magcobar (1975) A unique system for preparation and evaluation of high-temperature drilling fluids, SPE 5515

Rommetveit R, Bjørkevoll KS (1997) Temperature and pressure effects on drilling fluid rheology and ECD in very deep wells, SPE/IADC 39282

Street N (1958) Viscosity of clay suspensions. World Oil 147:151156

Sydansk RD (1983) Stabilizing Clays with Potassium Hydroxide, paper SPE 11721 presented at the SPE International Oilfield and Geothermal Chemistry Symposium, Denver

White WW, Zamora M, Svoboda CF (1996) Down hole measurement of synthetic based drilling fluid in offshore well qualify dynamic pressure and temperature distributions, SPE/IADC 35057

Zamora M (1996) On the HPHT rheology and hydraulic of syntheticbased drilling fluids. In: 5th Annual Meeting of the Nordic Rheology Society, Stavanger, Norway 